EGU2020-7077

https://doi.org/10.5194/egusphere-egu2020-7077

EGU General Assembly 2020

(c) Author(s) 2021. This work is distributed under

the Creative Commons Attribution 4.0 License.

\title{
Cooperative use of non invasive sensing methodologies for the geophysical monitoring of the archaeological park of Paestum
}

\author{
Luigi Capozzoli ${ }^{1,2}$, Francesco Soldovieri ${ }^{1}$, Enzo Rizzo ${ }^{2}$, Ilaria Catapano ${ }^{1}$, Giovanni Ludeno ${ }^{1}$, Gianluca \\ Gennarelli ${ }^{1}$, Gregory De Martino ${ }^{2}$, Francesco Uliano Scelza ${ }^{3}$, and Gabriel Zuchtriegel ${ }^{3}$ \\ ${ }^{1}$ National Research Council of Italy, Institute for Electromagnetic Sensing of the Environment, I-80124, Naples, Italy \\ ${ }^{2}$ National Research Council of Italy, Institute of Methodologies for Environmental Analysis, I-85050, Tito Scalo, Italy \\ ${ }^{3}$ Archaeological Park of Paestum, I-84047, Capaccio Paestum (SA)
}

The deployment of non-invasive sensing methodologies capable of providing information useful to characterize, monitor and manage archaeological sites represents a fundamental step for the conservation/preservation of cultural heritage assets. In the framework of the national project VESTA (funded by the Campania Region), several non invasive activities have been carried out for testing a novel approach of analysis including in situ methodologies, drone and satellite technologies.

This communication deals with a case study carried out at the monumental archaeological site of Paestum, sited in the southern Italy, where Greek settlers founded the ancient city of Poseidonia (6th century B.C.) [1]. At this site, geophysical surveys based on the combined use of magnetometric analyses [2], geoelectrical surveys [3] and ground-penetrating radar measurements [4] have been performed. Specifically, the areas immediately close to the temples of Ceres and Neptune have been investigated to identify unknown and buried archaeological features and characterise the paleo-morphological context. The different resolution and depth of investigations related to the application of each one of the considered methodologies as well as the use of tomographic methodologies for the data processing allowed the collection of images showing different subsurface features of the investigated area at different spatial scale. These images made possible the identification of anomalies of the subsoil, which were useful both to respond to the questions of the archaeologists and give new perspectives for managing the site. At the conference, the results of the integrated geophysical surveys, as well as their archaeological interpretation, will be presented with a focus on the cultural and social value of the "water resource" for the ancient city of Poseidonia.

[1] https://www.museopaestum.beniculturali.it/?lang=en

[2] A. Aspinall, C. Gaffney, A. Schmidt, A Magnetometry for archaeologists. Geophysical methods for archaeology, Altamira Press, Lanham (2008). 
[3] A. Binley, A. Kemna, DC resistivity and induced polarization methods. InHydrogeophysics Water and Science Technology Library; R. Yuram, S.S- Hubbard, S.S., Eds.; Springer: New York, NY, USA (2005).

[4] D. J. Daniels, Ground penetrating radar, IET (2004). 